\title{
СИСТЕМА СБАЛАНСИРОВАННЫХ ПОКАЗАТЕЛЕЙ КАК МЕТОД ОЦЕНКИ ЭФФЕКТИВНОСТИ ДЕЯТЕЛЬНОСТИ ПРЕДСТАВИТЕЛЬСТВ ХОЗЯЙСТВУЮЩИХ СУБЪЕКТОВ РОССИИ ЗА РУБЕЖОМ
}

\author{
(c) 2019 Бурцева Ксения Юрьевна \\ кандидат экономических наук, доцент Департамента учета, анализа и аудита \\ Финансовый университет при Правительстве Российской Федерации \\ 125993, г. Москва, Ленинградский пр-т, д.49 \\ (c) 2019 Петров Александр Михайлович \\ доктор экономических наук, профессор Департамента учета, анализа и аудита \\ Финансовый университет при Правительстве Российской Федерации \\ 125993, г. Москва, Ленинградский пр-т, д. 49 \\ E-mail:palmi@inbox.ru \\ (c) 2019 Гизатуллина Ольга Михайловна \\ кандидат экономических наук, доцент Департамента учета, анализа и аудита \\ Финансовый университет при Правительстве Российской Федерации \\ 125993, г. Москва, Ленинградский пр-т, д. 49 \\ E-mail: olgasergee@mail.ru
}

Стремительное развитие российской экономики, в том числе рост количества российских представительств хозяйствующих субъектов за рубежом, сопровождается процессами ужесточения конкуренции и изменения бизнес-среды, что приводит к усложнению бухгалтерского учета и оценки эффективности деятельности представительств отечественных компаний за рубежом.

Ключевые слова: представительства хозяйствующих субъектов России за рубежом, система сбалансированных показателей, оценка эффективности.

Стремительное развитие российской экономики, в том числе рост количества российских представительств хозяйствующих субъектов за рубежом, сопровождается процессами ужесточения конкуренции и изменения бизнес-среды, что приводит к усложнению бухгалтерского учета и оценки эффективности деятельности представительств отечественных компаний за рубежом. Анализ финансово-экономического состояния деятельности и оценки стратегической результативности представительств усложняется также спецификой правового регулирования процесса аккредитации и их функционирования в отдельных странах.

При открытии представительств российских предприятий за рубежом необходимо учитывать, что большинство стран в целях защиты национальных рынков от иностранных товаропроизводителей, жестко регулируют порядок создания и функционирования иностранных фирм специальными законодательными актами. В ряде стран при регистрации организаций с участием российских инвесторов, необходимо предварительное разрешение соответствующих национальных органов. Таким образом, для успешной работы российских представительств хозяйствующих субъектов за рубежом необходимо знать и соблюдать законодательство данной страны.

Огромное количество информационных потоков приводит к затруднениям в принятии рациональных управленческих решений. Руководители представительств рассчитывают, анализируют и оценивают большое количество индикаторов, реальную же эффективность их деятельности способны раскрыть объединенные в группы принципиально важные показатели, регулярный анализ которых позволит формировать объективное и достоверное мнение о результативности деятельности представительств. М. Браун на этот счет отмечал, что ключом к успеху организаций является идентификация небольшого количества принципиально важных индикаторов [1, с. 158]. На современном этапе развития и становления сети представительств российских компаний нахождение оптимального сочетания количества показателей оценки эффективности деятельности предста- 
вительств становится особенно актуальным.

Для формирования оптимального по количеству и составу пула показателей оценки рекомендуется применять давно зарекомендовавшую себя концепцию сбалансированных показателей (Balanced Scorecard), предложенную Д. Нортоном и Р. Капланом.

В зарубежных научных трудах данная тема раскрывается такими исследователями, как М.Г. Браун [1], Р. Каплан [2, 3], П.Р. Нивен [4], Э. Нили [5], Д. Нортон [2, 3], Н.-Г. Ольве [6], Хьюберт К. Рамперсад [7] и другими авторами.

В отечественной экономической литературе встречается достаточно большое количество вариаций перевода ее названия, наибольшую популярность получила «система сбалансированных показателей» (ССП). В основе концепции заложена идея о применении структурного подхода при формировании показателей оценки и управления компанией на основе их сбалансированности.

Balanced Scorecard - это система управления компанией посредством четко поставленных целей и задач в четырех основных проекциях [8], которые выделили основоположники концепции: финансы, клиенты, бизнес процессы, обучение и развитие. К четырем обозначенным аспектам могут добавляться другие, либо модифицироваться и в большей степени отражать специфику хозяйствования субъекта.

Изучение зарубежной литературы позволило выделить главные принципы формирования системы сбалансированных показателей $[1,2,3,4,5,6,7]$ :

- однозначность содержания, методики расчета и интерпретации показателей всеми структурных подразделениями хозяйствующего субъекта;

- охват основных аспектов функционирования компании и ключевых факторов успеха, которые необходимо учитывать при формировании стратегии организации;

- взаимосвязь показателей оценки ключевых аспектов функционирования хозяйствующего субъекта;

- простота и обоснованность расчета индикаторов;

- сопоставимость данных и возможность сравнивать показатели.

Современные условия глобализации диктуют необходимость изобретения новейших информационных возможностей и технологий.
Традиционной бухгалтерской отчетности недостаточно для удовлетворения потребностей менеджмента в информационных данных, что привело к возникновению системы сбалансированных показателей, содержащей как традиционные финансовые индикаторы, основанные на ретроспективных данных, так и прогнозные параметры будущего развития.

Российским представительствам хозяйствующих субъектов за рубежом рекомендуется использовать систему сбалансированных показателей как центральную информационно-обеспечивающую систему всех процессов управления [8]. Представительство может сформировать ССП для решения ограниченного числа задач: разработать понятные и доступные всем сотрудникам стратегию и миссию, сформировать общее мнение о методах и способах ее реализации, создать стратегическую карту и донести ее содержание всем работникам организации. Но большая ценность данной системы проявится в процессе ее трансформации в систему управлении [8], когда каждое управленческое решение будет приниматься на основе принципа сбалансированности показателей, их взаимозависимости и связи.

Разработка сбалансированной системы должна осуществляться в тесной увязке со стратегией представительства, которую рекомендуется формулировать по основным аспектам ССП (рисунок 1).

Стратегические направления развития должны быть отражены в системе показателей, также она должна включать: стратегические цели, аспекты ССП, индикаторы и единицы измерения, их целевые значения и порядок расчета.

Финансовый аспект является наиболее важным в формируемой ССП, так как важнейшей задачей любого представительства хозяйствующих субъектов за рубежом является экономическая целесообразность.

Не смотря на приверженность многих компаний концепции стейкхолдеров, основная идея которой заключается в соблюдении интересов всех стейкхолдеров при формировании и реализации стратегии, ключевыми заинтересованными в успешном развитии представительств группами являются их руководители и собственники. При формулировании общей концепции стратегической работы, собственники и менеджмент представительств хозяйствующих субъектов за 


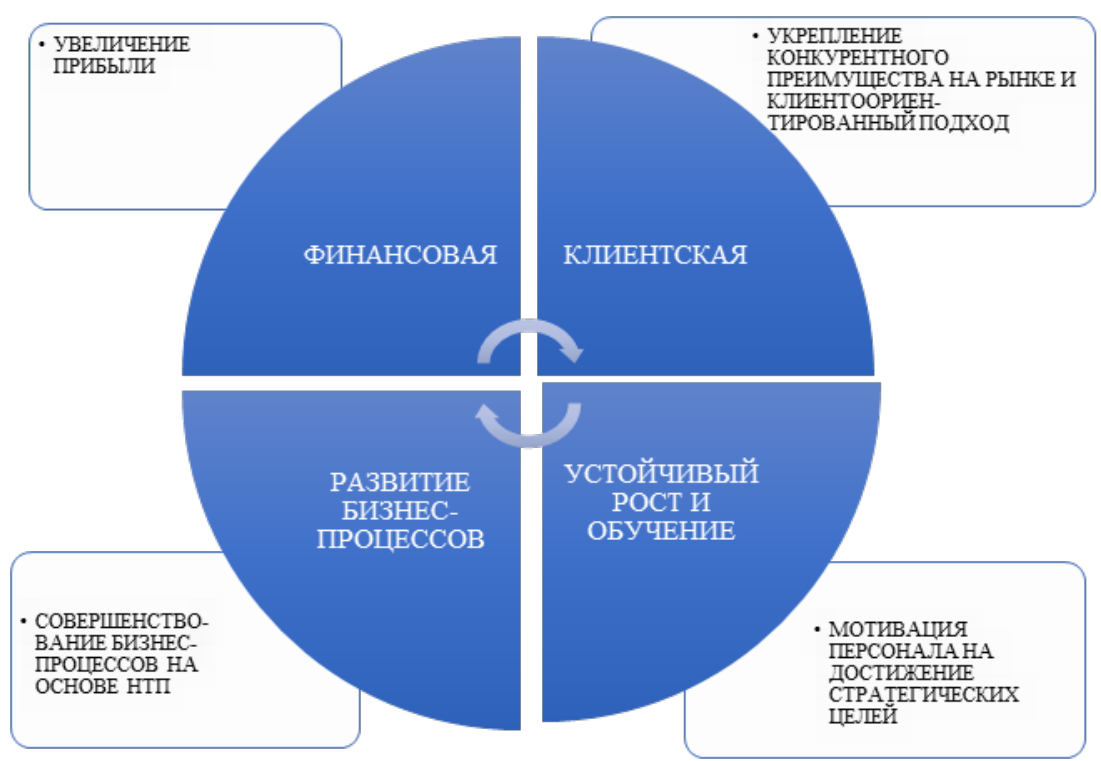

Puc. 1. Рекомендуемая стратегия развития представительств хозяйствующих субъектов за рубежом

Таблица 1. Рекомендуемые показатели анализа финансового состояния представительств хозяйствующих субъектов за рубежом во временном аспекте

\begin{tabular}{|c|c|c|}
\hline Виды информации & Показатели & Порядок расчета \\
\hline 1 & 2 & 3 \\
\hline $\begin{array}{l}\text { 1. Бухгалтерская финансо- } \\
\text { вая отчетность за предше- } \\
\text { ствующий период }\end{array}$ & \multicolumn{2}{|c|}{$\begin{array}{l}\text { Чистая прибыль за текущий год по сравнению с прошлым годом, выручка за } \\
\text { текущий год по сравнению с прошлым годом, средняя цена акции в текущем } \\
\text { месяце по сравнению с прошлым годом }\end{array}$} \\
\hline \multirow{11}{*}{$\begin{array}{l}\text { 2. Бухгалтерская финансо- } \\
\text { вая отчетность за отчет- } \\
\text { ный период }\end{array}$} & \multirow[t]{2}{*}{ Коэффициент текущей ликвидности } & $\begin{array}{l}\text { оборотные активы - расходы будущих } \\
\text { периодов }\end{array}$ \\
\hline & & $\begin{array}{l}\text { краткосрочные обязательства - до- } \\
\text { ходы будущих периодов - резервы } \\
\text { предстоящих расходов и платежей }\end{array}$ \\
\hline & \multirow{2}{*}{$\begin{array}{l}\text { Коэффициент обеспеченности соб- } \\
\text { ственными оборотными средствами }\end{array}$} & собственные оборотные средства \\
\hline & & оборотные активы \\
\hline & \multirow[t]{2}{*}{$\begin{array}{l}\text { Коэффициент финансовой устойчиво- } \\
\text { сти }\end{array}$} & $\begin{array}{l}\text { собственный капитал + долгосрочный } \\
\text { заемный капитал }\end{array}$ \\
\hline & & валюта баланса \\
\hline & \multirow{2}{*}{$\begin{array}{l}\text { Коэффициент концентрации привле- } \\
\text { ченных средств }\end{array}$} & привлеченные средства \\
\hline & & всего хозяйственных средств \\
\hline & $\begin{array}{l}\text { Коэффициент EVA (добавленная эко- } \\
\text { номическая стоимость) }\end{array}$ & $\begin{array}{l}\text { операционная прибыль - налоги - } \\
\text { стоимость капитала }\end{array}$ \\
\hline & \multirow{2}{*}{$\begin{array}{l}\text { Коэффициент MVA (добавленная ры- } \\
\text { ночная стоимость) }\end{array}$} & инвестированный капитал \\
\hline & & $\begin{array}{l}\text { рыночная стоимость всех собственных } \\
\text { и заемных средств организации }\end{array}$ \\
\hline \multirow[t]{5}{*}{ 3. Прогнозные данные } & \multirow{2}{*}{$\begin{array}{l}\text { Доля продаж за рубежом в общем объ- } \\
\text { еме продаж }\end{array}$} & объем продаж за рубежом \\
\hline & & общий объем продаж \\
\hline & \multirow[t]{2}{*}{ Показатель инвестиций в НИОКР } & чистая прибыль \\
\hline & & суммы инвестиций в НИОКР \\
\hline & $\begin{array}{l}\text { Уровень риска (вероятность банкрот- } \\
\text { ства) }\end{array}$ & \\
\hline
\end{tabular}


рубежом в большей мере концентрируют внимание на финансовом аспекте бизнеса, так как финансовые результаты является основным оценочным показателем эффективности хозяйственной работы. Поэтому повышенное внимание следует уделять формированию и анализу сбалансированных финансовых индикаторов.

В табл. 1 представлены сбалансированные финансовые показатели, которые могут быть использованы для анализа финансового состояния представительств хозяйствующих субъектов за рубежом во временном аспекте.

Для повышения своих конкурентных позиций на рынке представительства хозяйствующих субъектов за рубежом должны быть ориентированы на удовлетворение потребностей потребителей, снижение цен, повышение качества, улучшение обслуживания (табл. 2).

Проекция внутренних бизнес-процессов отражает основные процессы представительств хозяйствующих субъектов за рубежом, подлежащие усовершенствованию и развитию (табл. 3).

Таблица 2. Рекомендуемые показатели для анализа конкурентных позиций на рынке представительств хозяйствующих субъектов за рубежом

\begin{tabular}{|l|l|l|}
\hline \multicolumn{1}{|c|}{ Стратегические цели } & \multicolumn{1}{|c|}{ Показатели } & \multicolumn{1}{|c|}{ Порядок расчета } \\
\hline $\begin{array}{l}\text { Увеличение объема продаж. } \\
\text { Вытеснение конкурентов }\end{array}$ & Объем продаж за рубежом & $\begin{array}{l}\text { Отношение объема продаж за рубежом } \\
\text { планируемого года к объему продаж пре- } \\
\text { дыдущего года в процентах }\end{array}$ \\
\hline Увеличение объема продаж & $\begin{array}{l}\text { Количество заключенных дого- } \\
\text { воров на поставку }\end{array}$ & $\begin{array}{l}\text { Фактическое количество заключенных } \\
\text { контрактов на поставку }\end{array}$ \\
\cline { 2 - 3 } & Объем продаж за рубежом & $\begin{array}{l}\text { Отношение объема продаж за рубежом к } \\
\text { общему объему продаж в процентах }\end{array}$ \\
\hline $\begin{array}{l}\text { Удовлетворение потребностей } \\
\text { клиента по качеству }\end{array}$ & $\begin{array}{l}\text { Уровень дефектности у потре- } \\
\text { бителя }\end{array}$ & $\begin{array}{l}\text { Количество бракованных изделий на } \\
\text { миллион штук, информация поступает от } \\
\text { потребителя }\end{array}$ \\
\hline $\begin{array}{l}\text { Поставки «точно в срок» } \\
\text { Выполнение графика поставок }\end{array}$ & $\begin{array}{l}\text { Отношение количества партий поставок } \\
\text { без отклонения от графика к общему числу } \\
\text { партий поставок }\end{array}$ \\
\hline $\begin{array}{l}\text { Расширение ассортимента } \\
\text { изделий }\end{array}$ & $\begin{array}{l}\text { Доля новых изделий в общем } \\
\text { объеме продаж }\end{array}$ & $\begin{array}{l}\text { Отношение объема продаж новых изделий } \\
\text { к общему объему продаж в процентах }\end{array}$ \\
\hline
\end{tabular}

Таблица 3. Рекомендуемые показатели оценки эффективности бизнес-процессов

\begin{tabular}{|c|c|c|}
\hline Стратегические цели & Показатели & Порядок расчета \\
\hline \multirow[t]{2}{*}{$\begin{array}{l}\text { Повышение эффективности про- } \\
\text { цесса «Производство продукции» }\end{array}$} & $\begin{array}{l}\text { Производительность труда } \\
\text { на } 1 \text { рабочего }\end{array}$ & $\begin{array}{l}\text { Отношение производительности } \\
\text { труда планового года к предыдущему } \\
\text { году }\end{array}$ \\
\hline & Загрузка оборудования & $\begin{array}{l}\text { Отношение объема производства в } \\
\text { н/ч к фонду работы оборудования при } \\
\text { 2-сменном режиме с учетом коэф. } \\
\text { исп. оборудования }\end{array}$ \\
\hline \multirow[t]{2}{*}{$\begin{array}{l}\text { Повышение эффективности про- } \\
\text { цесса «Закупка комплектующих } \\
\text { изделий и материалов» }\end{array}$} & $\begin{array}{l}\text { Наличие альтернативных постав- } \\
\text { щиков }\end{array}$ & $\begin{array}{l}\text { Отношение номенклатуры комплек- } \\
\text { тующих, имеющих альтернативных } \\
\text { поставщиков, к общей номенклатуре } \\
\text { в\% }\end{array}$ \\
\hline & $\begin{array}{l}\text { Норматив складских запасов } \\
\text { ТМЦ }\end{array}$ & $\begin{array}{l}\text { Отношение фактических запасов ТМЦ } \\
\text { к нормативам запасов в\% }\end{array}$ \\
\hline \multirow{2}{*}{$\begin{array}{l}\text { Повышение эффективности } \\
\text { процесса «Поставка товарной } \\
\text { продукции» }\end{array}$} & Объем поставок & Информация по плану отгрузки \\
\hline & $\begin{array}{l}\text { Норматив складских запасов } \\
\text { готовой продукции }\end{array}$ & $\begin{array}{l}\text { Отношение фактических запасов ТМЦ } \\
\text { к нормативам запасов в\% }\end{array}$ \\
\hline $\begin{array}{l}\text { Формирование процесса «Инно- } \\
\text { вации» и повышение его эффек- } \\
\text { тивности }\end{array}$ & $\begin{array}{l}\text { Освоение и запуск в производ- } \\
\text { ство новых изделий }\end{array}$ & Акт освоения изделия \\
\hline $\begin{array}{l}\text { Формирование процесса «Инно- } \\
\text { вации» и повышение его эффек- } \\
\text { тивности }\end{array}$ & $\begin{array}{l}\text { Количество внедренных иннова- } \\
\text { ционных процессов }\end{array}$ & $\begin{array}{l}\text { Инвестиционная программа. Отче- } \\
\text { ты о внедрении инвестиционных } \\
\text { проектах }\end{array}$ \\
\hline
\end{tabular}


Таблица 4. Рекомендуемые показатели для оценки системы мотивации персонала

\begin{tabular}{|l|l|l|}
\hline \multicolumn{1}{|c|}{ Стратегические цели } & \multicolumn{1}{|c|}{ Показатели } & \multicolumn{1}{|c|}{ Порядок расчета } \\
\hline Повышение квалификации & $\begin{array}{l}\text { Количество часов обучения на 1 } \\
\text { работника по профессиональной } \\
\text { деятельности }\end{array}$ & $\begin{array}{l}\text { Отношение общего числа часов } \\
\text { обучения к общей численности }\end{array}$ \\
\cline { 2 - 3 } $\begin{array}{l}\text { Процент охвата работников } \\
\text { обучением по профессиональной } \\
\text { деятельности }\end{array}$ & $\begin{array}{l}\text { Отношение общего числа обучен- } \\
\text { ных работников к общей числен- } \\
\text { ности }\end{array}$ \\
\hline $\begin{array}{l}\text { Развитие информационных систем } \\
\text { управления предприятием }\end{array}$ & $\begin{array}{l}\text { Фондоотдача информационных } \\
\text { систем }\end{array}$ & $\begin{array}{l}\text { Отношение объема продаж к пер- } \\
\text { воначальной стоимости информа- } \\
\text { ционных систем }\end{array}$ \\
\cline { 2 - 3 } $\begin{array}{l}\text { Создание и внедрение системы } \\
\text { мотивации персонала, основан- } \\
\text { ной на системе сбалансированных } \\
\text { показателей }\end{array}$ & $\begin{array}{l}\text { Система сбалансированных пока- } \\
\text { знфелей }\end{array}$ & \begin{tabular}{l} 
Наличие документа \\
\hline
\end{tabular}
\end{tabular}

Развитие представительств хозяйствующих субъектов за рубежом является результатом объединения трех основных факторов:

- человеческих ресурсов;

- информационных систем;

- организационных бизнес-процессов.

В целях обеспечения долгосрочного присутствия на иностранном рынке, компания должно инвестировать средства в:

- повышение квалификации своих сотрудников;

- во внедрение современных информационных технологий;

- совершенствование внутри предприятия организационной системы и бизнес-процессов (табл. 4).

В заключении следует отметить, что в настоящее время систему сбалансированных показателей можно использовать в целях решения вопросов по управлению организацией, а рассмотренные особенности формирования сбалансированных показателей для оценки эффективности деятельности представительств хозяйствующих субъектов России за рубежом в соответствии с запросами потребителей информации помогут руководителям анализировать и оптимизировать свою деятельность.

\section{Библиографический список}

1. Браун Марк Г. Сбалансированная система показателей: на маршруте внедрения. Москва. 2005. 226 с.

2. Каплан Р.С. Организация, ориентированная на стратегию / Р. Каплан, Д. Нортон. Москва. 2003. 416 с.

3. Каплан Р.С. Сбалансированная система показателей. От стратегии к действию / Р.С. Каплан, Д.П. Нортон: пер с англ. 2-е изд., испр. и доп. Москва. 2006. 320 с.

4. Нивен П.Р. Сбалансированная система показателей: шаг за шагом: максимальное повышение эффективности и закрепление полученных результатов. Москва. 2004. 328 с.

5. Нили Э. Призма эффективности: карта сбалансированных показателей для измерения успеха в бизнесе и управления / Э. Нили, К. Адамс, М. Кеннерли. Москва. 2003. 398 с.

6. Оливе Н.-Г. Оценка эффективности деятельности компании. Практическое руководство по использованию сбалансированной системе показателей / Н.-Г. Оливе, Ж. Рой, М. Ветер: пер. с англ. Москва. 2004. 287 с.

7. Рамперсад X.К. Универсальная система показателей деятельности: Как достигать результатов, сохраняя целостность: пер. с англ. Москва. 2004. 352 с.

8. Бурцева К.Ю. Формирование сбалансированных финансовых показателей в бухгалтерском учете и их анализ (на примере предприятий -производителей автокомпонентов): дис... канд. экон. наук: защищена 27.12.2008: утв. 17.04.2009/К.Ю. Бурцева. - Самара.: Изд-во Самарский гос. экон. ун-т, 2008. 232 с. 